\title{
Pengaruh Sosial Ekonomi terhadap Pemilihan Pelayanan Kesehatan
} Maternal

\author{
Socio-Economic Impact on the Maternal Health Services Selection \\ Lely Khulafa' ur Rosidah¹, Rahma Novita Asdary² \\ 1,2Akbid Dharma Husada Kediri \\ Email: ${ }^{1}$ lely_khulafaur @akbiddharmahusadakdr.ac.id ${ }_{L}^{2}{ }^{2}$ itasdary@gmail.com
}

\section{INFO ARTIKEL}

\section{Sejarah artikel:}

Menerima 18 September 2021

Revisi 21 September 2021

Diterima 26 September 2021

Online 10 Oktober 2021

Kata kunci:

Sosial ekonomi

Jaminan Kesehatan Nasional

Fasilitas Pelayanan Kesehatan

Keywords:

Sosio Economic

National Health Insurance

Healthcare facility

\section{ABSTRAK}

Abstrak: Menurut statistikWHO, Angka kematian ibu (AKI) di negara-negara maju sekitar 12/100.000 kelahiran hidup, sedangkan di negara-negara berkembang dan berpenghasilan rendah adalah 239/100.000 kelahiran hidup. 99\% AKI diperkirakan terjadi di negara berkembang, padahal penyebab kematian dapat dicegah dengan kebijakan yang tepat mengingat tujuan SDGs salah satunya adalah menurunkan AKI. Penelitian ini mengevaluasi status sosial ekonomi berdasarkan keanggotaan Jaminan Kesehatan Nasional (JKN) terhadap pemilihan layanan kesehatan maternal. Penelitian ini merupakan penelitian cross-sectional menggunakan data SDKI 2017. Data ini digunakan untuk menilai proporsi status ekonomi dan keanggotaan JKN dan untuk mengukur hubungan keduanya dengan persalinan di Fasilitas pelayanan kesehatan (Fasyankes), dan persalinan oleh tenaga terampil serta PNC oleh tenaga terampil. Analisis Data menggunakan R software 3.6.3. dengan melakukan Propensity Score Matching (PSM) untuk mengurangi bias seleksi mandiri dengan menyeimbangkan variabel yang diamati antara kelompok responden berdasarkan status ekonomi dengan dan tanpa JKN Regresi Logistik,. Dari 5429 responden, 20.2\% adalah penduduk sangat miskin, 20.9\% penduduk miskin, 19.9\% menengah, 20.8\% kaya, dan $18.2 \%$ sangat kaya. Di antara penduduk tersebut, $61.4 \%$ memiliki keanggotaan JKN. Kesenjangan substansial dalam pemanfaatan layanan kesehatan maternal antara kelompok sangat miskin dan sangat kaya masih ada terutama memilih Fasyankes untuk proses persalinan sebesar 38 poin lebih rendah untuk kelompok sangat miskin (58,5\%) dibandingkan dengan kelompok sangat kaya (96,9\%) pada wanita yang memiliki keanggotaan JKN. Pemilihan Fasyankes untuk proses persalinan cenderung dilakukan oleh kelompok sangat kaya dibandingan oleh kelompok sangat miskin walaupun tercakup dalam keanggotaan JKN. Temuan ini konsisten dengan teori ekonomi bahwa cakupan asuransi kesehatan dapat mengurangi hambatan keuangan untuk perawatan dan meningkatkan penyerapan layanan.

\section{ABSTRACT}

Background: According to WHO data, the maternal mortality rate (MMR) in the developed countries is 12/100,000 live births, whereas it is 239/100,000 live births in developing and lowincome countries. Even though the cause of mortality may be prevented with the appropriate legislation, and one of the SDGs goals was to reduce MMR, it is estimated that 99 percent of all maternal fatalities occur in low-income countries. This study examines the impact of socioeconomic status on the choice of maternal health care based on participation in the National Health Insurance (JKN).

This cross-sectional research was based on data from the 2017 Demographic Health Survey (DHS). This dataset was utilized to determine the relationship between economic status and JKN membership and facility-based delivery, post-natal care (PNC), and PNC with skilled providers. Data analysis utilizing R software version 3.6.3 and Matching Propensity Score was used to decrease self-selection bias by balancing the observed variables between groups of depending respondents on wealth index with and without JKN to reduce self-selection bias and continued using logistic regression. $20.2 \%$ of the 5429 respondents were extremely poor, $20.9 \%$ were extremely poor, $19.9 \%$ were middle class, $20.8 \%$ were extremely wealthy, and $18.2 \%$ were extremely wealthy. JKN membership is held by $61.4 \%$ of these people. There were still significant disparities in the use of maternal health care between the very poor and the very wealthy, particularly in the choice of facility-based delivery, which is 38 points lower for the extremely poor (58.5\%) than the very wealthy $(96.9 \%)$ for women with JKN membership. Even though they are JKN members, the very wealthy choose facility-based delivery. This research supports the economic notion that having health insurance might lower financial barriers to care and boost service utilization. 


\section{PENDAHULUAN}

Pada tahun 2015 Sustainable Development Goals (SDGs) sebagai agenda negara di seluruh dunia dicetuskan dengan target pembangunan dan berlangsung sampai 2030. Beberapa sasaran capaian yang telah ditetapkan dalam rangka peningkatan derajat kesehatan dan gizi masyarakat antara lain Angka Kematian Ibu (AKI) 306/100.000 kelahiran hidup, Angka Kematian Bayi (AKB) 24/1.000 kelahiran hidup, prevalensi gizi buruk pada anak di bawah usia lima tahun sebesar 17/100.000, dan prevalensi stunting pada anak di bawah usia dua tahun sebesar 28/100.000. AKI telah turun 346 kematian menjadi 305 kematian ibu per 100.000 kelahiran hidup, namun masih jauh dari target MDGs yakni 102/100.000 kelahiran hidup yang ditetapkan pada tahun 2015. Indonesia, di sisi lain, harus berusaha untuk melampaui tujuan SDG dengan menurunkan AKI sampai di bawah 70 per 100.000 kelahiran hidup, menurunkan angka kematian neonatus menjadi 12 per 1000 kelahiran hidup, dan menurunkan angka kematian balita menjadi 25 per 1000 kelahiran hidup. Dibandingkan dengan negara-negara ASEAN lainnya, AKI Indonesia masih 9 kali lipat Malaysia, 5 kali Vietnam, dan hampir 2 kali Kamboja. Menurut statistik WHO, AKI di negara-negara maju diperkirakan 12/100.000 kelahiran hidup, sedangkan di negara-negara terbelakang adalah 239/100.000 kelahiran hidup. 99\% dari semua kematian ibu diperkirakan terjadi di negara berkembang, padahal penyebab kematian dapat dicegah dengan kebijakan yang tepat [1], [2][3].

Kematian ibu, didefinisikan sebagai kematian wanita saat hamil atau dalam 42 hari setelah penghentian kehamilan. Karena satu dari tiga kematian terkait kehamilan terjadi dari satu minggu hingga satu tahun kelahiran, sangat penting untuk memperhatikan kematian ibu yang terjadi tidak hanya dalam enam minggu, tetapi juga satu tahun [4]. Kematian ibu tidak hanya disebabkan oleh kegawatdaruratan yang terkait dengan kehamilan dan persalinan, tetapi juga oleh kualitas pelayanan kesehatan yang buruk, yang dapat dipengaruhi oleh status sosial ekonomi dan lokasi geografis. Tingginya AKI jamak terjadi pada populasi yang menghadapi ketimpangan sosial ekonomi. Beberapa penelitian telah menunjukan bahwa sosial ekonomi merupakan salah satu faktor risiko kematian ibu [5], [6].

Salah satu faktor risiko kematian ibu adalah status sosial ekonomi. Pre-eklampsia/ eklampsia, efek samping terkait anestesi, komplikasi obstetrik, atau kesulitan operasi caesar (Csection) menyebabkan lebih dari 100 kali rasio kematian ibu di beberapa negara berpenghasilan rendah (Low Income Countries - LICs) daripada di negara berpenghasilan tinggi (High Income Countries - HICs). Selain itu, ketimpangan dalam penggunaan pelayanan kesehatan ibu, seperti pelayanan antenatal care (ANC) di fasilitas kesehatan atau persalinan berbasis fasilitas, mempengaruhi buruknya kualitas kesehatan ibu di daerah pedesaan. Meskipun kematian ibu di HICs telah menurun secara substansial dalam beberapa dekade terakhir, masih terjadi sekitar 10 per 100.000 kelahiran [7].

Risiko tingginya AKI jamak terjadi di kabupaten/kota dengan cakupan kunjungan ANC yang rendah, cakupan persalinan oleh petugas kesehatan yang rendah, cakupan kunjungan post-natal care (PNC) yang rendah, jumlah rata-rata anak yang tinggi, rata-rata lama sekolah yang rendah bagi wanita usia subur, dan kemiskinan yang tinggi. Akses yang merata dan memadai ke layanan kesehatan bagi ibu merupakan instrumen penting bagi negaranegara untuk mencapai target SDGs [7].

Untuk mengurangi kematian terkait kehamilan/persalinan yang bisa dicegah, faktorfaktor yang dapat berkontribusi terhadap kematian ibu, seperti status sosial ekonomi yang berkaitan dengan pemilihan fasilitas kesehatan, harus diidentifikasi. Dengan mengetahui tentang faktor risiko lingkungan kritis, diharapkan dapat membantu mengurangi kematian ibu. Oleh karena itu penelitian kami bertujuan untuk menelaah lebih lanjut mengenai hubungan antara status sosial ekonomi dan pemilihan lokasi pelayanan kesehatan maternal.

\section{METODE PENELITIAN}

Penelitian ini merupakan penelitian cross-sectional karena menggunakan data crosssectional dari Survei Demografi dan Kesehatan Indonesia (SDKI) 2017, yang dilakukan oleh 
Badan Pusat Statistik bekerja sama dengan Badan Kependudukan dan Keluarga Berencana Nasional dan Badan Kependudukan dan Keluarga Berencana Nasional. SDKI menggunakan instrumen standar untuk mengukur pemanfaatan utama layanan ibu guna memastikan validitas dan komparabilitas hasil di dalam satu negara. Di Indonesia, survei menggunakan desain multi-stage stratified untuk menghasilkan sampel yang representatif dari 34 provinsi. Data SDKI 2017 digunakan untuk analisis utama, dengan SDKI 2012 digunakan untuk mengetahui penggunaan layanan JKN tahun 201. Data SDKI digunakan untuk menilai proporsi status ekonomi dan keanggotaan JKN dan untuk mengukur hubungan keduanya dengan persalinan di Fasyankes, dan persalinan oleh tenaga terampil serta PNC oleh tenaga terampil. Hasil utama ini dipilih karena mewakili intervensi utama yang membantu penurunan MMR. [8].

\section{Sample}

Wanita yang terdapat dalam SDKI 2017 sebanyak 49.627 orang. Kriteria dalam penelitian ini yakni wanita usia 15-49 tahun, sedang hamil atau postpartum $(<6$ bulan), mengisi kuesioner lengkap. Teknik sampling yang digunakan yakni convenient sampling

\section{Variable}

Independen

Status Ekonomi yang digunakan dalam penelitian ini berdasarkan Informasi mengenai Index Kemiskinan SDKI yang menggambarkan status sosial ekonomi rumah tangga dan digunakan untuk menghitung indeks kekayaan rumah tangga.

Variabel independen kedua yakni status keanggotaan JKN. Keanggotaan responden dalam JKN didtentukan dengan pertanyaan "Apakah Anda ditanggung oleh asuransi kesehatan?" dan "Apa bentuk asuransi kesehatan yang Anda miliki?"

Dependen

Persalinan di Fasyankes

Persalinan yang dilakukan di fasilitas kesehatan, antara lain puskesmas, klinik atau rumah bersalin, dan rumah sakit, serta persalinan yang dilakukan oleh dokter atau bidan swasta. Contoh: Semua kelahiran hidup dalam 5 tahun sebelum survei pada wanita usia 15-49
Persalinan oleh tenaga terampil

Persalinan dilakukan dengan bantuan tenaga terampil seperti dokter umum, dokter kandungan, bidan, dan perawat terampil. Contoh: Semua kelahiran hidup dalam 5 tahun sebelum survei pada wanita usia 15-49

PNC oleh tenaga terampil

Pelayanan kesehatan ibu diberikan selama 24 jam pertama sampai 3 hari setelah melahirkan (OF 1) oleh tenaga terampil. Contoh: Semua kelahiran hidup dalam 2 tahun sebelum survei pada wanita usia 15-49

\section{Etik}

Prosedur dan kuesioner survei SDKI 2017 telah ditinjau dan disetujui oleh ICF International Institutional Review Board (IRB), dan protokol survei telah ditinjau oleh ICF IRB, Kementerian Kesehatan RI, dan BKKBN untuk perlindungan manusia. mata pelajaran.

\section{Penentuan Index Kemiskinan}

Indeks kekayaan adalah ukuran gabungan dari standar hidup kumulatif rumah tangga. Indeks kemiskinan dihitung dengan menggunakan data yang mudah dikumpulkan tentang kepemilikan rumah tangga atas aset tertentu, seperti televisi dan sepeda; bahan yang digunakan untuk konstruksi perumahan; dan jenis akses air dan fasilitas sanitasi. Rumah tangga diberi skor berdasarkan jumlah dan jenis barang konsumsi yang mereka miliki, mulai dari televisi hingga sepeda atau mobil, dan karakteristik perumahan seperti sumber air minum, fasilitas toilet, dan bahan lantai. Skor ini diturunkan dengan menggunakan analisis komponen utama. Kuintil kekayaan nasional disusun dengan memberikan skor rumah tangga untuk setiap anggota rumah tangga biasa (de jure), memberi peringkat setiap orang dalam populasi rumah tangga berdasarkan skor mereka, dan kemudian membagi distribusinya menjadi lima kategori yang sama, masing-masing dengan $20 \%$ dari populasi [8].

\section{Statistik}

Untuk analisis data kami akan menggunakan Regresi Logistik dengan R software version 3.6.3. Karena kepemilikan asuransi kesehatan bukanlah proses acak dan tergantung pada karakteristik individu, kami menggunakan Propensity Score Matching (PSM) untuk mengurangi bias seleksi mandiri dengan menyeimbangkan kovariat yang diamati antara 
kelompok perempuan berdasarkan status ekonomi dengan dan tanpa JKN. Kami menggunakan perbedaan rata-rata standar absolut sebagai ukuran paling umum untuk memastikan keseimbangan dalam kelompok perlakuan dan kontrol sehubungan dengan variabel independen. Selanjutnya, kami menerapkan pengujian hipotesis berganda menggunakan prosedur Bonferroni dan Holm untuk mengontrol inflasi tipe 1 error (probabilitas menolak hipotesis nol yang benar) karena pengujian hipotesis nol secara simultan untuk tiga hasil utama

\section{HASIL PENELITIAN}

Karakteristik sampel penelitian kami dapat dilihat pada Table 1Table 1 Karakteristik Sampel. Secara keseluruhan, 61\% ibu yang baru melahirkan memiliki asuransi JKN pada tahun 2017. Mayoritas responden berusia kurang dari 35 tahun, menikah, dengan dua anak atau kurang, telah menyelesaikan pendidikan menengah, tidak memiliki pekerjaan, tidak terpapar internet dan surat kabar, dan tinggal di wilayah Jawa-Bali.

Meskipun masyarakat miskin dan hampir miskin memenuhi syarat untuk mendapatkan subsidi penuh atau sebagian melalui JKN, hanya ada sedikit perbedaan dalam distribusi responden di seluruh segmen kekayaan dalam populasi yang diasuransikan dan yang tidak diasuransikan, dengan pengecualian lebih sedikit responden dalam kekayaan tertinggi. kuintil di antara kelompok yang tidak diasuransikan. Proporsi sample yang menerima pelayanan kesehatan maternal lebih tinggi pada sampel yang termasuk dalam program JKN dibandingkan dengan yang tidak masuk dalam program JKN (tidak memiliki asuransi). Pada kategori kunjungan ANC 4+ terdapat 78,6\% sampel yang memiliki kanggotaan JKN dan tentu saja sampel yang tidak memiliki keanggotaan JKN memiliki presentasi lebih rendah yakni $71,0 \%$. Sedangkan pada kategori kunjungan ANC 4+ dan menerima komponen klinis ANC, sebanyak 23,4\% sample memiliki keanggotaan JKN, sedangkan 19,8\% yang ANC4+ dan menerima komponen klinis ANC tidak memiliki keanggotaan JKN.

Pada responden yang mendapat pelayanan tenaga terampil pada saat proses persalinan, sebanyak 94,4\% memiliki JKN. Pada sampel yang tidak memiliki JKN, pada saat persalinan mendapat pelayanan dari tenaga terampil sebanyak 90,6\%. Pada kelompok sampel yang memiliki JKN, yang memilih lokasi persalinan di fasyankes sebanyak $86,8 \%$, sedangkan kelompok sampel yang tidak memiliki JKN sebanyak $78,1 \%$ memilih lokasi persalinan di Fasyankes. Begitupun dengan variable lainnya, dimana kelompok sampel yang memiliki JKN memiliki proporsi yang lebih besar dalam mendapat pelayanan kesehatan maternal dibandingkan dengan kelompok yang tidak memiliki JKN (layanan PNC (90,2\% vs $85,4 \%) ; \quad$ PNC oleh tenaga terampil $(89,3 \%$ vs $83,7 \%))$.

Table 1 Karakteristik Sampel

\begin{tabular}{|c|c|c|c|c|c|c|}
\hline \multirow{2}{*}{ Variable } & \multicolumn{2}{|l|}{ Semua } & \multicolumn{2}{|l|}{ JKN } & \multicolumn{2}{|c|}{ Tidak masuk dalam JKN } \\
\hline & $\%$ & $\mathrm{~N}$ & $\%$ & $\mathrm{~N}$ & $\%$ & $\mathrm{~N}$ \\
\hline Sample Keseluruhan & 100.0 & 5429 & 61.4 & 3332 & 38.3 & 2097 \\
\hline \multicolumn{7}{|l|}{ Outcomes variables: } \\
\hline ANC 4+ & 75.6 & 4107 & 78.6 & 2618 & 71.0 & 1489 \\
\hline $\begin{array}{l}\text { ANC } 4^{+} \text {dan mendapat } \\
\text { komprehensif }\end{array}$ & 22.0 & 1194 & 23.4 & 780 & 19.8 & 414 \\
\hline Persalinan oleh tenaga terampil & 92.9 & 5045 & 94.4 & 2892 & 90.6 & 1900 \\
\hline Persalinan di Fasyankes & 83.5 & 4531 & 86.8 & 3145 & 78.1 & 1639 \\
\hline PNC & 88.4 & 4795 & 90.2 & 3004 & 85.4 & 1791 \\
\hline PNC oleh tenaga terampil & 87.1 & 4729 & 89.3 & 2097 & 83.7 & 1756 \\
\hline \multicolumn{7}{|l|}{ Variable Kontrol } \\
\hline \multicolumn{7}{|l|}{ Usia (tahun): } \\
\hline $15-24$ & 25.1 & 1364 & 22.9 & 764 & 28.6 & 600 \\
\hline $25-34$ & 51.9 & 2819 & 52.4 & 1745 & 51.2 & 1074 \\
\hline
\end{tabular}




\begin{tabular}{|c|c|c|c|c|c|c|}
\hline \multirow{2}{*}{ Variable } & \multirow{2}{*}{$\begin{array}{l}\text { Semua } \\
\%\end{array}$} & \multicolumn{3}{|c|}{ JKN } & \multicolumn{2}{|c|}{ Tidak masuk dalam JKN } \\
\hline & & $\mathrm{N}$ & $\%$ & $\mathrm{~N}$ & $\%$ & $\mathrm{~N}$ \\
\hline $35-42$ & 21.0 & 1140 & 22.4 & 747 & 18.7 & 392 \\
\hline $42-49$ & 2.0 & 107 & 2.3 & 76 & 1.5 & 31 \\
\hline \multicolumn{7}{|l|}{ Status Pernikahan } \\
\hline Tidak Menikah & 1.9 & 104 & 1.6 & 54 & 2.4 & 50 \\
\hline Menikah & 98.1 & 5325 & 98.4 & 3277 & 97.6 & 2047 \\
\hline \multicolumn{7}{|l|}{ Parity } \\
\hline 1 & 32.7 & 1776 & 32.4 & 1081 & 33.2 & 695 \\
\hline 2 & 35.3 & 1918 & 34.2 & 1139 & 37.1 & 778 \\
\hline 3 & 18.9 & 1027 & 19.5 & 648 & 18.1 & 379 \\
\hline 4 & 8.0 & 437 & 8.4 & 279 & 7.5 & 158 \\
\hline$>5$ & 5.0 & 271 & 5.5 & 184 & 4.2 & 87 \\
\hline \multicolumn{7}{|l|}{ Pendidikan } \\
\hline $\begin{array}{l}\text { Tidak bersekolah (tidak lulus pendidikar } \\
\text { dasar) }\end{array}$ & 6.5 & 352 & 6.4 & 212 & 6.7 & 140 \\
\hline Pendidikan dasar (lulus) & 18.0 & 979 & 16.9 & 562 & 19.9 & 417 \\
\hline Pendidikan menengah (tidak lulus) & 28.3 & 1535 & 25.6 & 852 & 32.6 & 683 \\
\hline Pendidikan menengah (lulus) & 31.0 & 1684 & 30.9 & 1029 & 31.2 & 655 \\
\hline Pendidikan tinggi & 16.2 & 879 & 20.3 & 677 & 9.6 & 202 \\
\hline \multicolumn{7}{|l|}{ Pekerjaan } \\
\hline Tidak bekerja & 56.7 & 3076 & 52.7 & 1755 & 63 & 1320 \\
\hline Petani & 6.8 & 367 & 6.2 & 206 & 7.6 & 160 \\
\hline Buruh & 24.9 & 1352 & 25.5 & 849 & 24 & 503 \\
\hline Pegawai & 11.7 & 634 & 15.6 & 520 & 5.4 & 114 \\
\hline \multicolumn{7}{|l|}{ Paparan terhadap Internet } \\
\hline Tidak sama sekali & 61.7 & 3351 & 57.5 & 1916 & 68.4 & 1435 \\
\hline$<1 \mathrm{x}$ per minggu & 30.3 & 1645 & 32.7 & 1090 & 26.5 & 556 \\
\hline$>1 \mathrm{x}$ per minggu & 8.0 & 433 & 9.8 & 326 & 5.1 & 107 \\
\hline \multicolumn{7}{|l|}{ Membaca Koran: } \\
\hline Tidak sama sekali & 4.1 & 220 & 3.8 & 128 & 4.4 & 92 \\
\hline$<1 \mathrm{x}$ per minggu & 12.9 & 702 & 13.3 & 443 & 12.3 & 259 \\
\hline$>1 \mathrm{x}$ per minggu & 83.0 & 4506 & 82.9 & 2760 & 83.3 & 1746 \\
\hline \multicolumn{7}{|l|}{ Index Kemiskinan } \\
\hline Sangat miskin & 20.2 & 1098 & 19.5 & 650 & 21.4 & 448 \\
\hline Miskin & 20.9 & 1135 & 19.2 & 640 & 23.6 & 495 \\
\hline Menengah & 19.9 & 1079 & 19.2 & 640 & 20.9 & 439 \\
\hline Kaya & 20.8 & 1129 & 20.6 & 688 & 21.1 & 442 \\
\hline Sangat Kaya & 18.2 & 987 & 21.4 & 714 & 13.0 & 273 \\
\hline \multicolumn{7}{|l|}{ Residensi } \\
\hline Rural & 51.9 & 2818 & 48.3 & 1610 & 57.6 & 1208 \\
\hline Urban & 48.1 & 2611 & 51.7 & 1721 & 42.4 & 890 \\
\hline \multicolumn{7}{|l|}{ Wilayah Tempat Tinggal: } \\
\hline Indonesia Timur & 3.5 & 192 & 3.9 & 131 & 2.9 & 62 \\
\hline Sulawesi & 7.4 & 402 & 8.9 & 297 & 5 & 105 \\
\hline Kalimantan & 6.0 & 326 & 5.2 & 174 & 7.2 & 152 \\
\hline Nusa Tenggara & 4.9 & 263 & 4.5 & 151 & 5.4 & 113 \\
\hline Sumatra & 22.7 & 1235 & 22.9 & 765 & 22.4 & 470 \\
\hline Jawa \& Bali & 55.4 & 3010 & 54.4 & 1814 & 57 & 1196 \\
\hline
\end{tabular}

Menurut model regresi logistik, peluang keanggotaan JKN diprediksi seperti yang tertera pada

Table 2. Jenis pekerjaan dan akses internet merupakan prediktor terpenting dari status partisipasi dalam JKN. Misalnya, wanita yang bekerja di sebagai pegawai 2,34 kali lebih mungkin untuk memiliki keanggotaan JKN dibandingkan dengan perempuan yang tidak memiliki pekerjaan $(95 \% \mathrm{CI}=1,74$ 3,16). Wanita yang terpapar internet minimal seminggu sekali memiliki kemungkinan 1,46 untuk memiliki keanggotaan JKN dibandingkan wanita yang tidak terpapar internet (95\% CI $=1,09-1,97)$. Akan tetapi tidak ada perbedaan signifikan dalam status keanggotaan JKN yang berdasarkan index kemiskinan (dibandingkan dengan kelompok termiskin). 
Table 2 Faktor yang berhubungan dengan keanggotakan Jaminan Kesehatan Nasional (JKN) 2017

\begin{tabular}{|c|c|c|c|}
\hline Variable & AOR & 95\% CI & P-Value \\
\hline \multicolumn{4}{|l|}{ Pekerjaan } \\
\hline \multicolumn{4}{|c|}{ Tidak bekerja (Referensi) } \\
\hline Petani & 0.96 & $(0.74-1.27)$ & 0.794 \\
\hline Buruh & 1.17 & $(0.99-1.40)$ & 0.073 \\
\hline Pegawai & 2.34 & $(1.74-3.16)$ & $<0.0001$ \\
\hline \multicolumn{4}{|l|}{ Akses Internet } \\
\hline \multicolumn{4}{|c|}{ Tidak sama sekali (Referensi) } \\
\hline$<1 x$ per minggu & 1.26 & $(1.07-1.47)$ & 0.004 \\
\hline$>1 x$ per minggu & 1.46 & $(1.09-1.97)$ & 0.012 \\
\hline \multicolumn{4}{|c|}{ Indeks Kemiskinan } \\
\hline \multicolumn{4}{|c|}{ Sangat Miskin (Referensi) } \\
\hline Miskin & 0.85 & $(0.67-1.08)$ & 0.173 \\
\hline Menengah & 0.89 & $(0.68-1.15)$ & 0.365 \\
\hline Kaya & 0.82 & $(0.62-1.08)$ & 0.150 \\
\hline Sangat Kaya & 1.04 & $(0.75-1.44)$ & 0.812 \\
\hline
\end{tabular}

AOR - adjusted odds ratio, $\mathrm{CI}$ - confidence interval

Berdasarkan sub-kelompok ekonomi menunjukkan bahwa perbedaan hasil yang terkait dengan pendaftaran JKN lebih besar untuk kelompok dengan sangat miskin dibandingkan dengan yang sangat kaya. Kesenjangan substansial dalam pemanfaatan layanan kesehatan ibu antara kelompok sangat miskin dan sangat kaya masih ada terutama memilih fasyankes untuk proses persalinan sebesar 38 poin lebih rendah untuk kelompok sangat miskin $(58,5 \%)$ dibandingkan dengan kelompok sangat kaya $(96,9 \%)$ pada wanita yang memiliki keanggotaan JKN.

Table 3 Pelayanan Kesehatan Maternal berdasarkan Status Ekonomi

\begin{tabular}{|c|c|c|c|c|}
\hline Grup & JKN & $\begin{array}{c}\text { Tidak Masuk } \\
\text { JKN } \\
\end{array}$ & $\begin{array}{c}\% \text { Rerata }(95 \% \\
\text { CI) } \\
\end{array}$ & P-value \\
\hline \multicolumn{5}{|l|}{ Persalinan oleh Tenaga Terampil } \\
\hline Sangat Miskin (Referensi) & 78.8 & 71.6 & $7.2(2.2-12.1)$ & 0.005 \\
\hline Miskin & 94.0 & 89.8 & $4.2(0.7-7.5)$ & 0.017 \\
\hline Menengah & 98.0 & 95.8 & $2.2(-0.8-5.2)$ & 0.156 \\
\hline Kaya & 99.1 & 96.0 & $3.1(0.0-6.1)$ & 0.051 \\
\hline Sangat Kaya & 99.3 & 100.0 & $-0.7(-1.3-(-0.1)$ & 0.021 \\
\hline \multicolumn{5}{|l|}{ Persalinan di Fasyankes } \\
\hline Sangat Miskin (Referensi) & 58.5 & 45.2 & $13.3(7.7-18.9)$ & $<0.0001$ \\
\hline Miskin & 82.2 & 69.7 & $12.5(7.1-17.9)$ & $<0.0001$ \\
\hline Menengah & 90.0 & 81.0 & $9.0(2.4-15.5)$ & 0.007 \\
\hline Kaya & 93.2 & 80.6 & $12.6(7.3-18.0)$ & $<0.0001$ \\
\hline Sangat Kaya & 96.9 & 91.9 & $5.0(-1.0-11.1)$ & 0.1 \\
\hline \multicolumn{5}{|l|}{ PNC oleh Tenaga Terampil } \\
\hline Sangat Miskin (Referensi) & 73.3 & 63.0 & $10.3(4.5-15.9)$ & $<0.0001$ \\
\hline Miskin & 86.9 & 80.7 & $6.2(1.3-11.0)$ & 0.013 \\
\hline Menengah & 91.0 & 88.2 & $2.8(-1.6-7.2)$ & 0.206 \\
\hline Kaya & 95.9 & 87.8 & $8.1(2.4-11.7)$ & 0.003 \\
\hline Sangat Kaya & 95.2 & 94.7 & $0.5(-3.6-4.6)$ & 0.808 \\
\hline
\end{tabular}

\% Rerata: average treatment effect on the treated (Kelompok yang memiliki keanggotaan JKN) 


\section{DISKUSI}

Pada tahun 2018, proporsi kunjungan ANC untuk wanita usia 10-54 tahun yaitu kunjungan pertama meningkat menjadi $96,1 \%$ dari $95,2 \%$ pada tahun 2013, sedangkan kunjungan ANC keempat meningkat menjadi $74,1 \%$ dari $70,0 \%$ pada tahun 2013, namun masih jauh dari $76,0 \%$ target yang ditetapkan dalam Renstra 2017 [9]. Namun, kualitas layanan untuk memastikan deteksi dini dan perawatan yang memadai bagi ibu hamil harus ditingkatkan. Bidan memimpin tugas dalam pemeriksaan kehamilan, mengenali kesulitan atau indikator komplikasi, membantu persalinan, dan melakukan evaluasi pascapersalinan. Jika bidan melihat indikator kesulitan yang tidak dapat diatasi, harus segera melakukan rujukan bagi ibu ke pusat kesehatan yang menawarkan Pelayanan Obstetri Neonatal Emergensi Dasar. Menurut data Kementerian Kesehatan tahun 2018, bidan mendukung 62,7\% persalinan yang dilakukan di bidan praktik mandiri (29\%), namun banyak yang masih dilakukan di rumah (16\%)[9].

Pada penelitian ini menunjukkan bahwa skema keanggotaan JKN di Indonesia berkaitan dengan pemilihan lokasi persalinan (di Fasyankes atau tidak) dan proses persalinan serta pasca persalinan oleh tenaga terampil. Temuan ini menambah semakin banyak data bahwa kepemilikan asuransi kesehatan terkait dengan perawatan kesehatan ibu seperti Persalinan di Fasyankes dan tenaga penolongnya[10]-[12]. Temuan kami konsisten dengan penelitian sebelumnya dari Indonesia dan LICs lainnya. Sebagian besar penelitian telah menemukan status ekonomi secara signifikan terkait dengan penggunaan layanan dam fasilitas kesehatan[13], [14].

Kemungkinan aksesibilitas sebagai hambatan utama lain yang muncul, termasuk masalah seperti jarak ke fasilitas kesehatan, sistem rujukan yang buruk, dan pengeluaran yang mungkin muncul harus dipertimbangkan. Penelitian sebelumnya menunjukkan bahwa kedekatan dengan fasilitas kesehatan merupakan faktor utama bagi ibu hamil dalam memilih layanan persalinan[15], [16]. Masalah seperti kurangnya pilihan transportasi dan infrastruktur transportasi yang buruk dapat mengakibatkan peningkatan biaya kunjungan perawatan kesehatan. Untuk keluarga yang masuk dalam kategori miskin dengan kemampuan keuangan terbatas, masalah jarak adalah alasan yang umum dicatat untuk tidak menggunakan pelayanan kesehatan sebagaimana mestinya. Hal ini menarik untuk diteliti pada penelitian berikutnya. Program asuransi kesehatan harus mendorong perempuan untuk melakukan perjalanan ke fasilitas kesehatan dengan menyediakan cakupan untuk transportasi rujukan dan rawat inap di rumah sakit, terutama untuk rumah tangga dengan kemampuan keuangan terbatas.

\section{SIMPULAN}

Kualitas layanan kesehatan maternah untuk memastikan deteksi dini dan perawatan yang memadai harus ditingkatkan. Pada penelitian ini menunjukkan bahwa skema keanggotaan JKN di Indonesia yang terkait dengan pemilihan lokasi persalinan di Fasyankes atau tidak. Temuan ini menambah semakin banyak data bahwa kepemilikan asuransi kesehatan terkait dengan perawatan kesehatan ibu seperti Persalinan di Fasyankes dan tenaga penolongnya.

\section{REFERENSI}

[1] A. D. Laksono, R. Rukmini, and R. D. Wulandari, "Regional disparities in antenatal care utilization in Indonesia," PLoS One, vol. 15, no. 2, pp. 1-13, 2016, doi: 10.1371/journal.pone.0224006.

[2] United Nation, "The Sustainable Development Goals Report 2021," New York, 2021.

doi:

10.29171/azu_acku_pamphlet_k3240_s878_2 016.

[3] WHO, "Trends in maternal mortality: 1990 to 2015: estimates by WHO, UNICEF, UNFPA, World Bank Group and the United Nations Population Division," Geneva, 2016.

[4] WHO, "THE GLOBAL HEALTH OBSERVATORY - Explore a world of health data."

https://www.who.int/data/gho/indicatormetadata-registry/imr-details/26.

[5] A. Lindquist, M. Knight, and J. J. Kurinczuk, 
"Variation in severe maternal morbidity according to socioeconomic position: a UK national case-control study," BMJ Open, vol. 3, no. 6, p. e002742, 2013.

[6] J. Novignon, B. Ofori, K. G. Tabiri, and M. H. Pulok, "Socioeconomic inequalities in maternal health care utilization in Ghana," Int. J. Equity Health, vol. 18, no. 1, pp. 1-11, 2019.

[7] A. B. Patel et al., "Development of the Global Network for Women's and Children's Health Research's socioeconomic status index for use in the network's sites in low and lower middle-income countries.," Reprod. Health, vol. 17, no. Suppl 3, p. 193, Dec. 2020, doi: 10.1186/s12978-020-01034-2.

[8] S. Indonesia, M. of H.- Kemenkes, and ICF, "Indonesia Demographic and Health Survey 2017." BKKBN, BPS, Kemenkes, and ICF, Jakarta, Indonesia, 2018, [Online]. Available: http://dhsprogram.com/pubs/pdf/FR342/ FR342.pdf.

[9] R. I. Kemenskes, "Laporan hasil riset kesehatan dasar (Riskesdas)." Jakarta, 2016.

[10] N. U. Z. Gardezi, "Public health insurance and birth outcomes: evidence from Punjab, Pakistan.," Health Policy Plan., vol. 36, no. 1, pp. 1-13, Mar. 2021, doi: 10.1093/heapol/czaa115.

[11] W. Zeng, G. Li, H. Ahn, H. T. H. Nguyen, D.

\begin{abstract}
S. Shepard, and D. Nair, "Cost-effectiveness of health systems strengthening interventions in improving maternal and child health in low- and middle-income countries: a systematic review.," Health Policy Plan., vol. 33, no. 2, pp. 283-297, Mar. 2018, doi: 10.1093/heapol/czx172.
\end{abstract}

[12] A. B. Comfort, L. A. Peterson, and L. E. Hatt, "Effect of health insurance on the use and provision of maternal health services and maternal and neonatal health outcomes: a systematic review.," J. Health. Popul. Nutr., vol. 31, no. 4 Suppl 2, pp. 81-105, Dec. 2013.

[13] C. E. Phelps, Health economics. Routledge, 2017.

[14] W. Bank, World development indicators 2014. The World Bank, 2014.

[15] T. Ganchimeg et al., "Pregnancy and childbirth outcomes among adolescent mothers: a World Health Organization multicountry study.," BJOG, vol. 121 Suppl 1, pp. 40-48, Mar. 2014, doi: 10.1111/14710528.12630.

[16] J. V. de O. Franchi, S. M. Pelloso, R. A. P. Ferrari, and A. A. M. Cardelli, "Access to care during labor and delivery and safety to maternal health.," Rev. Lat. Am. Enfermagem, vol. 28, p. e3292, 2020, doi: 10.1590/15188345.3470.3292. 